\title{
Variabilidade entre plantas de azevém para caracteres relacionados à precocidade
}

\author{
Variability for early forage production related traits among italian ryegrass plants \\ Andréa Mittelmann ${ }^{1}$ Carlos Otávio Costa Moraes $^{2}$ César Henrique Espírito Candal Poli ${ }^{3}$ \\ Márcio Zamboni Neske ${ }^{4}$ Tatiana Lima de Brandolt ${ }^{4}$ Leidiane Cougo Anillo $^{4}$
}

\begin{abstract}
O objetivo deste trabalho foi estudar a variabiliRESUMO dade intrapopulacional existente para caracteres relacionados à produção precoce de matéria seca e duração do ciclo vegetativo em uma população de azevém anual (Lolium multiflorum). Foram avaliadas 500 plantas para o número de dias para o florescimento, além de vigor, altura de planta e número de afilhos, medidos 90 dias após a semeadura. Houve grande variabilidade para os caracteres avaliados $e$ as correlações entre produção precoce e duração do ciclo vegetativo foram baixas, indicando que é possível obter cultivares de azevém com maior período de utilização.
\end{abstract}

Palavras-chave: Lolium multiflorum, forrageiras, vigor, altura, ciclo vegetativo

\section{ABSTRACT}

The objective of this study was to verify intrapopulation variability for traits related to early forage production and heading date in an annual ryegrass population (Lolium multiflorum). A total of 500 plants were evaluated for heading date. Vigor, plant height and tiller number were evaluated 90 days after sowing. There was great variability for all the traits and correlations between early production traits and heading date were low. It is possible to obtain ryegrass cultivars with a larger period of utilization.

Key words: Lolium multiflorum, forages, vigor, plant height, heading date

Os caracteres realmente importantes em uma espécie forrageira são aqueles que afetam o desenvolvimento das plantas, a persistência e o valor nutritivo, mas a importância relativa de cada caráter dependerá em grande parte dos estresses impostos pelo ambiente e pelo tipo de produção animal envolvido. De maneira geral, a principal característica é a produtividade, ou seja, a capacidade de produzir altos rendimentos. Além da produção total de matéria seca, a distribuição ao longo do tempo é importante. Após o florescimento, as gramíneas tendem a perder qualidade, pela redução na proporção de lâmina foliar em relação a outros tecidos. Portanto, genótipos tardios devem ser selecionados. Entretanto, na Região Sul do Brasil a produção precoce de matéria seca é de grande importância, uma vez que o período de maior deficiência de forragem ocorre no outono-inverno.

Grande variabilidade intrapopulacional tem sido observada em azevém para diferentes caracteres, inclusive duração do ciclo vegetativo (CASTRO, 1999). A possibilidade de se obter ganhos significativos por seleção massal em populações de azevém foi demonstrada com o desenvolvimento da cultivar Empasc 304 - Serrana, a qual foi, na média de três anos de experimentação, $9 \%$ mais produtiva que a população original. A seleção foi efetiva também para precocidade, pois nos cortes realizados até o mês de agosto a superioridade na produção de matéria seca foi da ordem de 13\% (DALL'AGNOL et al., 1989).

O objetivo deste trabalho foi estudar a variabilidade intrapopulacional existente para caracteres relacionados à produção precoce de matéria seca e duração do ciclo vegetativo.

Foram avaliadas 500 plantas de uma população de azevém anual (Lolium multiflorum) coletada na região da Campanha do Rio Grande do

\footnotetext{
${ }^{1}$ Engenheiro Agrônomo, Doutora, Embrapa Gado de Leite, Caixa Postal 403, 96001-970, Pelotas-RS. E-mail: andream@cpact.embrapa.br. Autor para correspondência.

${ }^{2}$ Engenheiro Agrônomo, MSc, Embrapa Pecuária Sul

${ }^{3}$ Engenheiro Agrônomo, Doutor, Embrapa Pecuária Sul

${ }^{4}$ Alunos do Curso de Graduação em Ciências Biológicas da Universidade Regional da Campanha (URCAMP).
} 
Sul. As plantas foram semeadas de forma espaçada, sendo o espaçamento entre linhas e entre plantas de $0,5 \mathrm{~m}$. A semeadura foi realizada com cinco sementes por cova e após a germinação foi realizado desbaste, mantendo-se uma planta por cova. Noventa dias após a semeadura, foram avaliados os caracteres vigor (nota de um a cinco, sendo $1=$ baixo vigor e $5=$ alto vigor), número de afilhos e altura $(\mathrm{cm})$. Para avaliação do florescimento (número de dias, contados a partir da data da semeadura), foram marcadas semanalmente com lã colorida as plantas que haviam emitido a primeira espiga. O experimento foi realizado em área da Embrapa Pecuária Sul em Bagé, RS. A data de semeadura foi 7/ 5/2002. A análise estatística compreendeu a análise descritiva e as estimativas de associação entre caracteres pela análise de correlações. Estas análises foram feitas através do software SAS (SAS Institute, 1990).

As notas atribuídas para o vigor contemplaram toda a escala de notas, evidenciando a existência de variabilidade entre plantas (Tabela 1). Para altura de planta a média foi $20,8 \mathrm{~cm}$, com desviopadrão de 6,20. Para o número de afilhos, a média foi 16,6 e o desvio-padrão 8,78. Esta variabilidade fenotípica é influenciada tanto por aspectos genéticos como por efeitos de ambiente (FALCONER, 1981). Estes três caracteres, avaliados no mês de agosto, 90 dias após a semeadura, indicam a existência de diferenças entre as plantas no que se refere ao desenvolvimento inicial. A partir da variabilidade existente, é possível obter variedades de azevém que apresentem maior produção de matéria seca durante o inverno. O número de dias para o florescimento, variou de 161 a 196, com média de 175,8. Esta diferença de mais de um mês entre plantas de uma mesma população, embora sujeita a efeitos de ambiente, indica um grande potencial para a seleção do caráter.

Tabela 1 - Média, desvio padrão, valores mínimo e máximo para os caracteres vigor (nota de 1 a 5), altura de planta $(\mathrm{cm})$, número de afilhos e florescimento (dias) em uma população de azevém. Bagé, 2002.

\begin{tabular}{llccc}
\hline & Vigor & Altura & n. de afilhos & florescimento \\
\hline Mínimo & 1 & 5,5 & 2 & 161 \\
Máximo & 5 & 38,7 & 52 & 196 \\
Média & 2,38 & 20,78 & 16,58 & 175,76 \\
Desvio Padrão & 0,83 & 6,20 & 8,79 & 7,88 \\
\hline
\end{tabular}

As notas atribuídas visualmente para o vigor foram significativamente correlacionadas com os dados de altura da planta e número de afilhos (Tabela 2). Entretanto, o valor destas correlações foi intermediário, não sendo indicado seu uso exclusivo na seleção entre plantas de azevém. Correlações negativas foram observadas entre o número de dias para o florescimento e os demais caracteres, porém com valores extremamente baixos. Isso demonstra que a precocidade no desenvolvimento vegetativo não está necessariamente ligada a um florescimento precoce. Assim, seria possível prolongar o período de produção de matéria seca e de utilização da pastagem de azevém.

Estes resultados indicam que há variabilidade intrapopulacional para os caracteres avaliados, sendo possível desenvolver cultivares de azevém com maior duração do período vegetativo.

Tabela 2 - Estimativas dos coeficientes de correlação fenotípica entre os caracteres vigor (nota de 1 a 5), altura de planta $(\mathrm{cm})$, número de afilhos e florescimento (dias) em uma população de azevém. Bagé, 2002.

\begin{tabular}{lccc}
\hline & Altura & n. de afilhos & florescimento \\
\hline Vigor & $0,66^{*}$ & $0,61^{*}$ & $-0,28^{*}$ \\
Altura & - & $0,33^{*}$ & $-0,31^{*}$ \\
n. de afilhos & & - & $-0,13^{*}$ \\
\hline
\end{tabular}

*significativo a $1 \%$

\section{REFERENCIAS BIBLIOGRÁFICAS}

CASTRO, C.M. Caracterização morfológica e molecular de populações de azevém anual. 1999. 68f. Dissertação (Mestrado em Agronomia) - Universidade Federal de Pelotas.

DALL'AGNOL, M.; GOMES, K.E.; VIDOR, M.A. Competição de cultivares de azevém anual. In: REUNIÃO ANUAL SOCIEDADE BRASILEIRA DE ZOOTECNIA, 26., 1989, Porto Alegre. Anais... Porto Alegre: SBZ, 1989. p.36.

FALCONER, D.S. Introduction to quantitative genetics. 2.ed. New York : Longman Scientific e Technical, 1981. 438p.

SAS INSTITUTE. SAS/STAT user's guide. Cary: Statistical Analysis System Institute, 1990. 956p. 